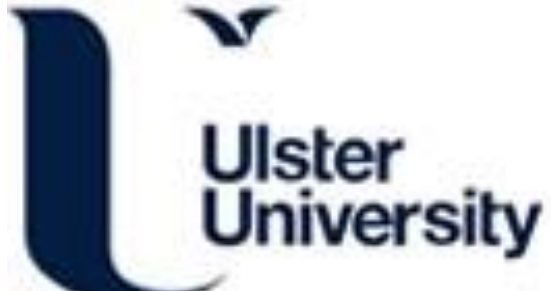

Development of a Health Related Quality of Life Measure for Adolescents and Young Adults Following Invasive Meningococcal Disease

Mark, S., Coen, P. G., Borg, J., Booy, R., Viner, R. M., \& Christie, D. (Accepted/In press). Development of a Health Related Quality of Life Measure for Adolescents and Young Adults Following Invasive Meningococcal Disease. Applied Research in Quality of Life, 11(3), 971-982. https://doi.org/10.1007/s11482-015-9416-9

Link to publication record in Ulster University Research Portal

Published in:

Applied Research in Quality of Life

Publication Status:

Accepted/In press: 21/06/2015

DOI:

10.1007/s11482-015-9416-9

Document Version

Publisher's PDF, also known as Version of record

\section{General rights}

Copyright for the publications made accessible via Ulster University's Research Portal is retained by the author(s) and / or other copyright owners and it is a condition of accessing these publications that users recognise and abide by the legal requirements associated with these rights.

\section{Take down policy}

The Research Portal is Ulster University's institutional repository that provides access to Ulster's research outputs. Every effort has been made to ensure that content in the Research Portal does not infringe any person's rights, or applicable UK laws. If you discover content in the Research Portal that you believe breaches copyright or violates any law, please contact pure-support@ulster.ac.uk. 


\title{
Development of a Health Related Quality of Life Measure for Adolescents and Young Adults Following Invasive Meningococcal Disease
}

\author{
Mark Shevlin ${ }^{1}$ Pietro G. Coen ${ }^{2} \cdot$ Jennie Borg $^{3}$ •

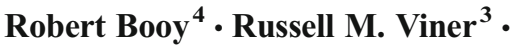 \\ Deborah Christie 5
}

Received: 23 February 2015 / Accepted: 21 June 2015 / Published online: 12 July 2015

(C) Springer Science+Business Media Dordrecht and The International Society for Quality-of-Life Studies (ISQOLS) 2015

\begin{abstract}
This study describes the key areas that matter to adolescent survivors of Invasive Meningococcal Disease (IMD). Satisfaction with Life After Meningitis is a brief multidimensional measure of health related quality of life that is reliable and correlates with criterion variables in a theoretically meaningful way. To develop a Health Related Quality of Life (HRQoL) measure for adolescent and young adult survivors of (IMD) we used a cross-sectional study and focus groups. The study was conducted in two phases. In Phase 1 a pool of potential items were generated based on the following: a review of existing measures, focus groups with IMD survivors, and an expert group consultation. Phase 2 involved administration of the questionnaire to a sample of adolescent and young adult IMD survivors. Factor analysis suggested a correlated four factor solution: Wellbeing, Positive about Future, Social Support, and Confidence. These factors were significantly correlated in a theoretically predictable way with scores from the Beck Depression Inventory (correlations ranged from -0.77
\end{abstract}

Deborah Christie

Deborah.christie@uclh.nhs.uk

1 School of Psychology, Faculty of Life and Health Sciences, University of Ulster at Magee Campus, L'Derry, BT48 7JL Northern Ireland, UK

2 Centre for Child Health, Barts and the London School of Medicine and Dentistry, Queen Mary College, University of London, London, UK

3 UCL Institute of Child Health, London, UK

4 National Centre for Immunisastion research and Surveillance, Children's Hospital at Westmead and University of Sydney and Sydney Institute of Emerging Infectious Diseases and Biosecurity, Sydney, Australia

5 Paediatric and Adolescent Psychology, University College London Hospitals, 6th Floor Central, 250 Euston Road, London NW1 2PG, UK 
to -0.81 ) and the eight domains of the SF-36 Health Survey (correlations ranged from 0.32 to 0.79 ). The reliability of all subscales was high ranging from 0.85 to 0.92 . The Satisfaction with Life After Meningitis (SLAM) questionnaire is a HRQoL self-report measure that produces reliable scores and is appropriate for use with young survivors of IMD. There is also evidence of concurrent validity with existing measures of physical and psychological well-being.

Keywords Adolescence Young adults - Invasive meningococcal disease $\cdot$ Health related quality of life · Questionnaire

$\begin{array}{ll}\text { Abbreviations } \\ \text { BDI } & \text { Beck depression inventory } \\ \text { IMD } & \text { Invasive meningococcal disease } \\ \text { HRQoL } & \text { Health related quality of life } \\ \text { QOL } & \text { Quality of life } \\ \text { SLAM } & \text { Satisfaction with life after meningitis }\end{array}$

\section{Introduction}

Measures of health related quality of life (HRQoL) are increasingly important in the evaluation of illness outcomes and healthcare (Garratt et al. 2002) HRQoL is not just defined by what an individual can or cannot do, but also the meaning that he/she attributes to different levels of functioning (Gill and Feinstein 1994). HRQoL is a multidimensional concept including aspects of life that are not generally considered as 'health', such as income, freedom, and the quality of the environment. For survivors of conditions such as IMD which cause high rates of complications particularly in adolescents and young adults. (Harrison et al. 2001; Erickson and De Wals 1998; Sander et al. 1984) all aspects of life can become health related (Guyatt 1993) because of the way IMD affects their overall quality of life. Complications include major physical and neurological complications of the disease in early childhood including cognitive impairment, epilepsy, vasculitis, arthritis, and sensorineural hearing loss (Fellick et al. 2001; Baraff et al. 1993; Naess et al. 1994) Outcome studies which have included adolescents have shown they suffer high rates of physical sequelae, complain of general problems with physical health and report memory and concentration problems and reduced quality of life (Erickson and De Wals 1998; Sander et al. 1984; Christie et al. 2011; Viner et al. 2012). The most important aspects of HRQoL are physical and mental health, social function, role and general well being (WHO 1995; Ridley 1997). The goal of health care is to maximize the health component of quality of life (Bowling 1995).

Little is known regarding HRQoL in adolescent survivors of IMD with no specific instruments to measure HRQoL post-IMD. Adolescence is characterised by attempts to establish autonomy and independence, close personal relationships, educational goals and financial security. Theses developmental changes make it inappropriate to use either child or adult instruments in young people (Eiser and Morse 2001)

Generic adolescent instruments include the Child Health and Illness Profile Adolescent Edition (Starfield et al. 1993), the Quality of Life Profile - Adolescent Version (Raphael, et al. 1996) and the 16 Dimensions scale (Apajasalo et al. 1996 ) 
However, none of these were designed to assess the unique impairments that follow IMD. The sequelae of IMD may be too specific to be detected by generic quality of life (QOL) instruments, which do not address the individuals perceived quality of life affected by disease, illness or disability and may underestimate the severity of deficits. Specific instruments for other conditions are similarly unlikely to be useful in assessing HRQoL in IMD survivors.

In our outcome study of IMD in adolescent survivors compared with age and sex matched controls (Borg, et al. 2010) significant impairments were found in social, physical, mental health and cognitive domains. Survivors rated their overall QOL using a simple likert scale. They rated it as significantly worse than peers and deteriorating since the episode of IMD. This simple approach did not indicate which deficits were of greatest concern for the individuals concerned. Disease-specific HRQoL instruments provide greater sensitivity and specificity in addressing patient concerns in specific conditions such as asthma, epilepsy, and arthritis (Eiser and Morse 2001) (Deyo and Patrick 1989). The main aim of this study was to develop a IMD-specific HRQoL questionnaire for young people.

\section{Patients and Methods}

Young people were recruited from Scotland, Northern Ireland, and England through 3 UK charities providing support related to IMD: The Meningitis Trust; Meningitis Research Foundation and Meningitis UK. The charities contacted all adolescents and young adults aged 15 to 27 years from their databases with clinically proven IMD within the previous 5 years. Fanilies that were interested in participation contacted the researchers. The young people who participated in each phase of the project had varied physical complications of IMD, were different ages and gender, and were either at school or university, unemployed or in full-time employment. Informed written consent or assent was obtained for participation from both the young person and parent/carer. The study was approved by the Research Ethics Committee of University College London.

\section{Procedure}

\section{Phase 1. Item Development and Refinement by Focus Group and Expert Group}

Phase 1 identified relevant domains and generated a large pool of potential items in four stages in order to create a baseline questionnaire. First, a literature review of generic adolescent measures identified existing domains. Second, six professionals with experience in developing HRQoL instruments were invited to form a multi-disciplinary Expert Group. Panel members included psychologists $(n=2)$, clinical research fellows $(n=2)$, dermatologist $(n=1)$ and a chief scientific officer $(n=1)$.

Comments from the Expert Group were analysed using Delphi which is an appropriate consensus method (Jones and Hunter 1995; Linstone and Turoff 1975) that has been used extensively in the context of health care (Bellamy et al. 1991; Chin et al. 
1990; Khan et al. 1994; Mobily et al. 2007; Oranga and Nordberg 1993) and provides an effective structure for analysis of group communication.

Thirdly a semi-structured interview was used in focus groups attended by 18 English speaking young adult survivors of IMD (mean age 19.3 years: thirteen $(72.2 \%)$ female). Participants were asked to (1) describe their understanding of HRQoL, (2) describe the effect of IMD on different areas of their life, (3) identify the most important effect IMD had had on their life and (4) identify areas of life that should be included on a HRQoL questionnaire for young survivors of IMD. The groups lasted approximately $90 \mathrm{~min}$. Each participant was given a $£ 20$ voucher for attending. Conversations were tape-recorded, transcribed verbatim and analysed to generate a list of domains, themes and sub-themes using Interpretive Phenomenological Analysis.

Four domains were identified; physical, social, psychological and cognitive. Members of the Expert Group were asked to prioritise the domains identified in order of potential impact on HRQoL in young people after IMD. A series of questions informed by the three previous stages were used to create a draft questionnaire. Questions were written to be clear, unambiguous, and age appropriate using straightforward language. Focus groups participants and the Expert Group were sent the questions for review. Comments on pertinence, appropriateness, clarity, readability and duplication were incorporated into the final draft which contained a total of 93 items. The Flesch Reading Ease score was used to assess the questions. This rates text on a 100-point scale; the higher the score, the easier it is to understand the document. The questionnaire achieved a score of 57 with the majority of standard documents aiming for a score of approximately 60 to 70 . All items were presented using a 5-point Likert response scale that indicated frequency (1 'None of the Time' -5 'All of the Time'), intensity (1 'Not at All' - 5 'A Great Deal'), or satisfaction (1 'Very Dissatisfied' - 5 'Very Satisfied'). All scores were coded so that high values indicated higher quality of life.

\section{Phase 2.: Questionnaire Testing}

Fifty-one young adults were recruited for phase two and agreed to complete the questionniare (mean age $24.8(\mathrm{SD}=1.56)$ years: twenty five (49\%) female). Participants lived with their parents $(41.2 \%)$, a partner $(35.3 \%)$, or in shared accommodation (9.8\%). Most participants were employed (82.4\%). $9.8 \%$ were self-employed and $3.9 \%$ at university. Mean age of onset of IMD was 16.9 years (SD=1.48). Most participants had been admitted to ICU $(76.5 \%)$ for an average of 6.75 days (SD=9.96). The majority reported both meningitis and septicaemia $(56.9 \%)$ with meningitis alone $(31.4 \%)$ or septicaemia alone $(5.9 \%)$. Each young person was interviewed for approximately $2 \mathrm{~h}$ and completed the draft SLAM questionnaire, the SF-36 Health Survey (SF36: Ware et al. 1993a, b) and the Beck Depression Inventory (BDI: Beck 1987).

The SF-36 is a 36-item self-report measure that assesses physical and psychological wellbeing and functioning across eight domains; physical functioning, limited by physical problems, limited by emotional problem, social functioning, mental health, energy, pain, and general health perception. Responses are summed and transformed to a 0 to 100 scale with higher scores reflecting positive evaluations. Extensive research on the psychometric properties of scores derived from the measure suggest acceptable 
levels of reliability and validity (Ware et al. 1993a, b; Jenkinson et al. 1996; Jenkinson et al. 1999)

The Beck Depression Inventory (BDI: Beck 1987) is a standardized 21-item selfreport measure that assesses the presence and severity of symptoms of depression. Higher total scale scores reflect higher levels of severity. The BDI produces reliable and valid scores for adults (Arnau et al. 2001) and adolescents (Krefetz et al. 2002) in a diverse range of clinical and non-clinical samples.

Questionnaire Refinement using Factor Analysis A process of item deletion for the 93 baseline items was conducted using two exclusion criteria. First, to avoid floor or ceiling effects all items that had $80 \%$ or more of the responses in one category were eliminated. Second all items that were skewed $(> \pm 1)$ were eliminated to ensure adequate scale score variability. The factor structure of the remaining items was determined using exploratory factor analysis. The models were estimated using maximum likelihood based on a covariance matrix using LISREL8.70 (Jöreskog and Sörbom 2004). Models with two or more factors employed an oblique (promax) rotation. Eight models were tested; models included zero to seven factors. For each model the chi-square statistic and the root-mean-square error of approximation (RMSEA: Steiger 1990) were used to assess model fit. A chi-square which was not significant and a RMSEA value less than .05 were used as criteria for acceptable model fit. In addition parsimony was considered; the best model should be significantly better than the model with one less factor and not significantly different to the model with one more factor. Reliability for each subscale was estimated using Cronbach's alpha.

Concurrent validity was assessed by correlating mean sub-scale scores with the SF36 and BDI

\section{Results}

The first and second exclusion criteria resulted in removal of 22 and 43 items respectively. The original item pool was therefore reduced to 28 items after the initial set of exclusion rules were applied. For these items the Kaiser-Meyer-Olkin measures the sampling adequacy was satisfactory $(0.82)$ and Bartlett's Test of Sphericity was significant $\left(\chi^{2}=1177.05, \mathrm{df}=378, p<.01\right)$; indicating that the data were suitable for factor analysis. The fit statistics for the factor analyses are reported in Table 1.

Both the chi-square and the RMSEA indicated that the model with four factors was acceptable in terms of model fit. The four-factor model was significantly better than the three-factor model $\left(\Delta \chi^{2}=72.99, \Delta \mathrm{df}=26, p<.05\right)$ and not significantly different from the five-factor model $\left(\Delta \chi^{2}=36.99, \Delta \mathrm{df}=25, p>.05\right)$. The factor loadings are reported in Table 2. The solution had few cross loadings greater than .30 .

The highest loading items for each factor made the labelling of factors 1,2 , and 4 straightforward. Items tapping a range of negative moods, emotions, feeling and somatic experiences loaded on Factor 1. As all the items are scored towards higher quality of life this factor was labelled "Wellbeing". Many items that loaded on Factor 2 related to positive evaluations about future, resilience, and self-efficacy. The factor was 
Table 1 Fit statistics for alternative factor analytic models of SLAM items

\begin{tabular}{llllllll}
\hline Factors & $\chi^{2}$ & $\mathrm{df}$ & $\mathrm{p}$ & $\Delta \chi^{2}$ & $\Delta \mathrm{df}$ & $\mathrm{p}$ & RMSEA \\
\hline 0 & 1246.98 & 406 & 0.00 & & & & 0.20 \\
1 & 615.21 & 377 & 0.00 & 631.78 & 29 & 0.00 & 0.11 \\
2 & 477.50 & 349 & 0.00 & 137.70 & 28 & 0.00 & 0.08 \\
3 & 388.00 & 322 & 0.01 & 89.51 & 27 & 0.00 & 0.06 \\
4 & 315.00 & 296 & 0.21 & 72.99 & 26 & 0.00 & 0.03 \\
5 & 278.02 & 271 & 0.37 & 36.99 & 25 & 0.06 & 0.02 \\
6 & 243.05 & 247 & 0.56 & 34.96 & 24 & 0.07 & 0.00 \\
7 & 214.10 & 224 & 0.67 & 28.96 & 23 & 0.18 & 0.00 \\
\hline
\end{tabular}

labelled "Positive about Future". All the items that loaded on Factor 4 were related to social activities and was labelled "Social Support". Only three items loaded on Factor 3 which was not clearly defined as two items had large cross loadings with the "Positive about Future" factor. Confidence was a core element of the three items so Factor four was labelled "Confidence".

Factor correlations, estimates of reliability (Cronbach's alpha), and mean sub-scale scores are reported in Table 3 . All four factors were positively correlated with correlations ranging from 0.37 to 0.59 . The correlations were not too high as to suggest redundancy. The reliability of all subscales was high ranging from 0.85 to 0.92

The scores on each subscale were summed and correlated with scores on the eight domains of the SF-36 and the total BDI scores. The correlations are reported in Table 4.

Each of the subscales correlated positively with each of the SF-36 domains, and the correlations were all statistically significant. The subscales also demonstrated a degree of unique predictive utility demonstrated by the correlations within each domain being different. The correlations with the BDI scores were all negative and statistically significant. The correlations were all similar in magnitude.

\section{Discussion}

The aim of this study was to develop a multidimensional self-report measure of HRQoL for adolescent and young adult IMD survivors. An initial pool of items derived from focus groups was administered to a sample of young adult survivors. Initial item reduction was based on distributional criteria which trimmed the total number of candidate items to twenty-eight. Factor analysis suggested four correlated factors each with acceptable levels of reliability. These factors were associated with SF-36 domains and BDI scores in a theoretically predictable manner.

Factor loadings reported in Table 2 show that for each factor all the loadings are higher than .30 (Nunnally and Bernstein 1994). These high factor loadings explain the high levels of reliability reported for each subscale. The "Wellbeing" and "Positive about Future" subscales that represent these factors were comprised of 12 and 8 items respectively. The remaining subscales were comprised of 3 and 5 items. Given the high reliability of these there may be an opportunity to further shorten the scale by removing 
Table 2 Factor loadings for maximum likelihood (promax rotated) factor analysis of SLAM items

\begin{tabular}{|c|c|c|c|c|}
\hline Item During the past 4 weeks... & $\begin{array}{l}\text { Factor } 1 \\
\text { Wellbeing }\end{array}$ & $\begin{array}{l}\text { Factor } 2 \\
\text { Positive } \\
\text { about } \\
\text { Future }\end{array}$ & $\begin{array}{l}\text { Factor } 3 \\
\text { Confidence }\end{array}$ & $\begin{array}{l}\text { Factor } 4 \\
\text { Social } \\
\text { Support }\end{array}$ \\
\hline I have felt sad & 0.852 & & & \\
\hline I have felt like crying & 0.816 & & & \\
\hline I have felt achieved things & 0.669 & & & \\
\hline I have felt worried & 0.624 & & & \\
\hline I feel physically tired and worn out & 0.537 & & & \\
\hline I have been feeling down & 0.523 & & & \\
\hline I have felt irritable & 0.518 & & & \\
\hline I have felt mentally tired & 0.465 & & & 0.312 \\
\hline I have felt happy & 0.406 & & & 0.302 \\
\hline I have felt healthy & 0.400 & & & \\
\hline I have felt cheerful & 0.378 & & & 0.347 \\
\hline I have felt self-critical & 0.373 & & 0.340 & \\
\hline I am confident that I can fulfil any ambitions I have & & 0.973 & & \\
\hline I am confident that I can do the things I want to do & & 0.921 & & \\
\hline I am confident that I can make plans for the future & & $\mathbf{0 . 8 3 3}$ & & \\
\hline $\begin{array}{l}\text { I am confident that I can get on with my life as best } \\
\text { as I can }\end{array}$ & & 0.578 & 0.396 & \\
\hline I am confident that I can deal with any difficulties I encounter & & 0.571 & 0.322 & \\
\hline I feel my self-confidence is high after meningococcal disease & & 0.554 & & \\
\hline Health was not a worry & & 0.522 & & \\
\hline not getting enough sleep & & 0.364 & & \\
\hline I am confident that I can enjoy life to the full & & 0.501 & 0.638 & \\
\hline $\begin{array}{l}\text { I am confident that I can meet new people and } \\
\text { go to new places }\end{array}$ & & 0.368 & 0.621 & \\
\hline I have felt lacking confidence & & & 0.474 & \\
\hline I have met new people & & & & 0.966 \\
\hline I have socialised with friends & & & & 0.952 \\
\hline Do you enjoy social activities? & & & & 0.677 \\
\hline siblings have been understanding and helpful & & & & 0.448 \\
\hline
\end{tabular}

Highest factor loading for each item in bold. Loadings $<.30$ not shown

some of the items with lower factor loadings from the 'Wellbeing' and 'Positive about Future' subscales. The factor correlations are moderate, ranging from 0.374 to 0.590 with, a mean correlation of .491. This suggests that each subscale should have differential predictive utility.

For scores from a HRQoL scale to have clinical utility the scale also needs to be related to other theoretically related constructs. Each subscale was significantly related to a range of measures of physical and psychological wellbeing and functioning. For many of the criterion variables, the correlations were high, indicating convergent 
Table 3 Factor correlation and Cronbach's alpha (95\% confidence intervals) for the four-factor model of SLAM items

\begin{tabular}{lllll}
\hline & Wellbeing & Positive about Future & Confidence & Social Support \\
\hline Wellbeing & 1.000 & & & \\
Positive about Future & 0.533 & 1.000 & & \\
Confidence & 0.478 & 0.462 & 1.000 & \\
Social Support & 0.590 & 0.512 & 0.374 & 1.000 \\
Scale mean (SD) & $2.58(0.75)$ & $3.18(0.97)$ & $2.91(1.05)$ & $2.49(1.03)$ \\
Cronbach's alpha & 0.919 & 0.917 & 0.888 & 0.851 \\
& $(0.882,0.948)$ & $(0.878,0.947)$ & $(0.822,0.932)$ & $(0.771,0.908)$ \\
\hline
\end{tabular}

validity. Additionally, there was also some evidence of discriminate validity. For example the associations between Limited by Physical Problems sores and scores on the SLAM subscales were quite different, being non-significant for the 'Positive about Future' subscale but high and statistically significant for the 'Confidence' subscale.

SLAM is slightly shorter than the SF-36 with the potential for further reduction of items. It therefore takes slightly less time to complete and it's focus on what is important to survivors of invasive meningococcal disease makes it a more suitable measure of HRQoL than other more generic scales

\section{Limitations}

We acknowledge this study had a number of limitations. The young people were recruited through charities that offer support to families that have experienced meningitis. These families have actively sought help and therefore it is possible that this sample represents young people who are more likely to be experiencing difficulties. In addition over $75 \%$ of the sample had been admitted to ICU. This means that the sample was highly self-selected and potentially likely be young people who have experienced a greater impact of meningitis. As the questionnaire is designed to identify difficulties we believe that this is an appropriate sample and that the scale therefore has high face validity

There was a higher percentage of females in the focus groups (phase one) than in the group that completed the questionnaires (phase two). Our clinical experience is that females are more likely to be interested in 'talking' than young men and therefore this will have contributed to those young people that contacted us expressing an interest to take part in the focus groups. Young people self selected to participate and we did not wish to refuse individuals that expressed an interest in contributing to the research in order to balance gender in the arms.

The sample size was relatively small which means that replication is necessary in order to establish the stability of the factor structure that was reported. However, recent research has shown that exploratory factor analysis with small samples, such as 50, can successfully recover the factor structure particularly if the factor loadings are high, small number of factors, and large number of variables (de Winter et al. 2009). The "Confidence" factor was not well defined and was measured by only three items. Two of the items cross-loaded on the "Positive about Future" factor so subsequent research 


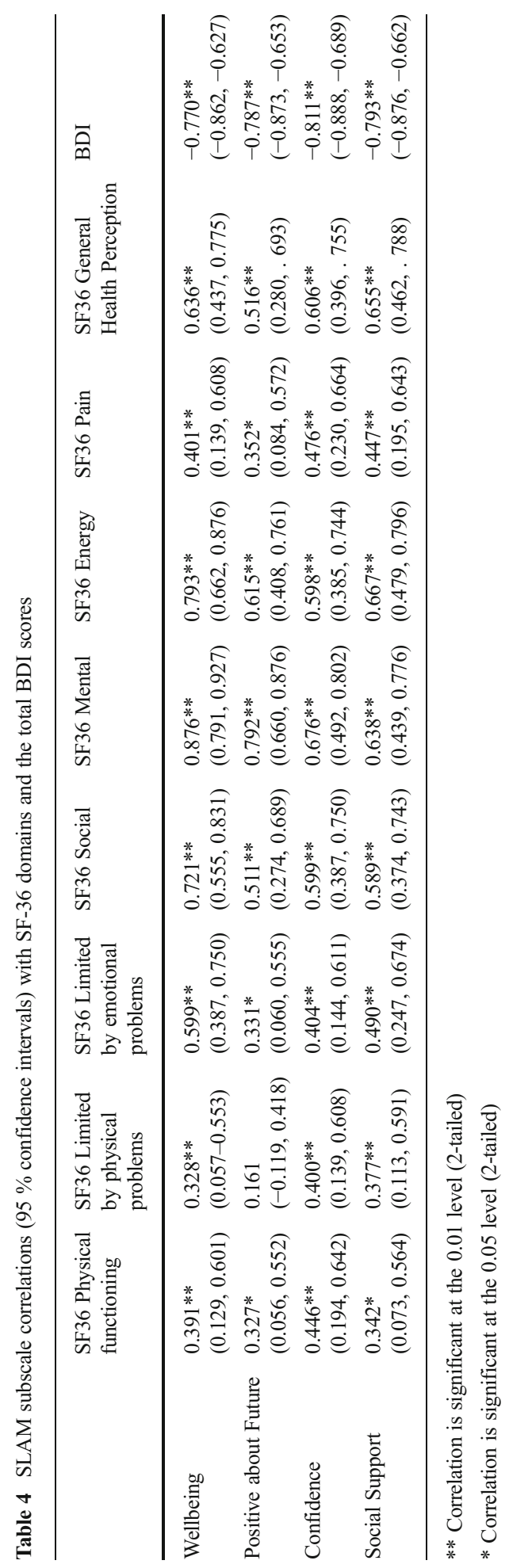


is needed to ensure that the "Confidence" factor is providing additional and unique information. This may require a broader range of criterion variables to be used in subsequent validation studies.

All the variables in this study were measured using self-report and so the associations may be attributable to shared method variance. Future research could also include HRQoL ratings from other sources such as clinicians, carers, and friends to estimate inter-rater reliability. Furthermore it would be useful to assess temporal changes in HRQoL and how these relate to changes in clinical status (Aspesberro et al. 2015). We do not currently have plans to validate the scale in other languages although we would be very pleased if any studies of meningitis survivors completed in different countries would be interested in collaborating .

The aim of the study was to produce a disease specific scale that tapped into the particular issues for meningitis survivors. Interestingly the instrument does not focus on specific aspects of meningococcal disease and is relatively generic. However it has been constructed by young people who are survivors and therefore reflects the key areas that matter to these young people rather what the investigators may have included had they not consulted the young people in the focus groups.

\section{Conclusion}

This study reports a four-factor model of quality of life based on twenty eight items. The Satisfaction with Life After Meningitis (SLAM) questionnaire is a brief multidimensional measure of HRQoL that produces scores that correlate with criterion variables in a theoretically meaningful way. It is proposed that the questionnaire undergoes further psychometric evaluation using a larger sample and a broader range of criterion variables.

Acknowledgments The development of SLAM was funded by the Meningitis Trust. The Meningitis Trust were not involved in the design and conduct of the study; collection, management, analysis, and interpretation of the data; preparation, review, or approval of the final manuscript.

We would like to thank all the young people who gave their time to meet with us and share their ideas and experiences.

Financial Disclosure The authors have no financial relationships relevant to this article to disclose.

Conflict of Interest The authors have no conflicts of interest to disclose.

Funding Source The study was funded by the Meningitis Trust

\section{References}

Apajasalo, M., Sintonen, H., Holmberg, C., Sinkkonen, J., Aalberg, V., Pihko, H., Siimes, M. A., Kaitila, I., Mäkelä, A., Rantakari, K., Anttila, R., \& Rautonen, J. (1996). Quality of life in early adolescence: a sixteen-dimensional health-related measure (16D). Quality of Life Research, 5(2), 205-11.

Arnau, R. C., Meagher, M. W., Norris, M. P., \& Bramson, R. (2001). Psychometric evaluation of the Beck Depression Inventory-II with primary care medical patients. Health Psychology, 20, 112-119. 
Aspesberro, F., Mangione-Smith, R., \& Zimmerman, J.J. (2015). Health-related quality of life following pediatric critical illness. Intensive Care Med. 2015 Apr 8. DOI 10.1007/s00134-015-3780-7.

Baraff, L. J., Lee, S. I., \& Schriger, D. L. (1993). Outcomes of bacterial meningitis in children: a metaanalysis. Pediatric Infectious Disease Journal, 12, 389-94.

Beck, A. T. Beck Depression Inventory. 1987. USA, Psychological Corporation.

Bellamy, N., Anastassiades, T. P., Buchanan, W. W., Davis, L., Lee, P., \& McCain, G. A. (1991). Rheumatoid arthritis anti-rheumatic trials. III. Setting the delta for clinical trials of anti-rheumatic drugs-results of a consensus development (Delphi) exercise. Journal of Rheumatology, 18, 1908-1915.

Borg, J., Christie, D., Coen, P., Booy, R., \& Viner, R. (2010). Outcomes of meningococcal disease in adolescence: a prospective matched cohort study. Pediatrics, 123(3), e502-9.

Bowling, A. (1995). Measuring disease: a review of disease-specific quality of life measurement scales. Open University Press.

Chin, J., Sato, P. A., \& Mann, J. M. (1990). Projections of HIV infections and AIDS cases to the year 2000. Bulletin of the World Health Organization, 68, 1-11.

Christie, D., Viner, R., Knox, K., Coen, P., Wang, H., El Bashir, H., Patel, B., \& Booy, R. (2011). Long-term outcomes of pneumococcal meningitis in childhood and adolescence. European Journal of Pediatrics. doi:10.1007/s00431-010-1390-5.

de Winter, J. C. F., Dodou, D., \& Wieringa, P. A. (2009). Exploratory factor analysis with small sample sizes. Multivariate Behavioral Research, 44, 147-181.

Deyo, R. A., \& Patrick, D. L. (1989). Barriers to the use of health status measures in clinical investigation, patient care, and policy research. Medical Care, 27, S254-S268.

Eiser, C. \& Morse, R. (2001). "Quality of life measures in chronic diseases of childhood.”, Health Technol Assess, vol. 5.

Erickson, L., \& De Wals, P. (1998). Complications and sequelae of meningococcal disease in Quebec, Canada. Clinical Infectious Diseases, 26, 1159-1164.

Fellick, J. M., Sills, J. A., Marzouk, O., Hart, C. A., Cooke, R. W., \& Thomson, A. P. (2001). Neurodevelopmental outcome in meningococcal disease: a case-control study. Archives of Disease in Childhood, 85(1), 6-11.

Garratt, A., Schmidt, L., Mackintosh, A., \& Fitzpatrick, R. (2002). Quality of life measurement: bibliographic study of patient assessed health outcome measures. BMJ, 324, 1417.

Gill, T. M., \& Feinstein, A. R. (1994). A critical appraisal of the quality-of-life measurements. JAMA, 272, 619-626.

Guyatt, G. H., Feeny, D. H., \& Patrick, D. L. (1993). Measuring health-related quality of life. Annals of Internal Medicine, 118, 622-629.

Harrison, L. H., Pass, M. A., Mendelsohn, A. B., Egri, M., Rosenstein, N. E., Bustamante, A. R. N., et al. (2001). 2001 Invasive meningococcal disease in adolescents and young adults. JAMA, 286(6), 694-9.

Jenkinson, C., Layte, R., Wright, L., et al. (1996). The UK SF-36: An analysis and interpretation manual. Oxford: Health Services Research Unit.

Jenkinson, C., Stewart-Brown, S., Petersen, S., \& Paice, C. (1999). Assessment of the SF-36 version 2 in the United kingdom. Journal of Epidemiology and Community Health, 53, 46-50.

Jones, J., \& Hunter, H. (1995). Consensus methods for medical and health services research. British Medical Journal, 311, 376-380.

Jöreskog, K., \& Sörbom, D. (2004). LISREL 8.70. Chicago: Scientific Software Inc.

Khan, J. P., Bernstein, S. J., Leape, L. L., Hilborne, L. H., Park, R. E., \& Parker, L. (1994). Measuring the necessity of medical procedures. Medical Care, 32, 357-365.

Krefetz, D. G., Steer, R. A., Gulab, N. A., \& Beck, A. T. (2002). Convergent validity of the Beck Depression Inventory-II with the Reynolds Adolescent Depression Scale in psychiatric inpatients. Journal of Personality Assessment, 78, 451-460.

Linstone, H. A. \& Turoff, M. (1975). The Delphi Method: Techniques and Applications. Addison-Wesley, Reading, Mass.

Mobily, P. R., Herr, K. A., \& Kelly, L. S. (2007). Cognitive-behavioural techniques to reduce pain: a validation study. International Journal of Nursing Studies, 30, 537-548.

Naess, A., Halstensen, A., Nyland, H., Pedersen, S. H., Moller, P., Borgmann, R., et al. (1994). Sequelae one year after meningococcal disease. Acta Neurologica Scandinavica, 89(2), 139-142.

Nunnally, J., \& Bernstein, I. (1994). Psychometric theory. New York: McGraw-Hill.

Oranga, H. M., \& Nordberg, E. (1993). The Delphi panel method for generating health information. Health Policy and Planning, 8, 405-412.

Raphael, D., Rukholm, E., Brown, I., Hill-Bailey, P., \& Donato, E. (1996). The quality of life profile adolescent version: background, description and initial validation. 
Ridley, S.A., Chrispin, P.S., Scotton, H., Rogers, J., \& Lloyd, D. (1997). Changes in quality of life after intensive care: comparison with normal data. Anaesthesia, 52(3), 195-202.

Sander, J., Bay, D., \& Gedde-Dahl, T. W. (1984). Late sequelae after meningococcal disease. A controlled study in young men. NIPH Annals, 7, 3-11.

Starfield, B., Bergner, M., Ensminger, M., Riley, A., Ryan, S., Green, B., McGauhey, P., Skinner, A. \& Kim, S (1993). Adolescent health status measurement: development of the child health and illness profile. Pediatrics, 91(2).

Steiger, J. H. (1990). Structural model evaluation and modification: an interval estimation approach. Multivariate Behavioural Research, 25, 173-180.

Viner, R. M., Booy, R., Johnson, H., Edmunds, W. J., Hudson, L., Bedford, H., \& Christie, D. (2012). Outcomes of invasive meningococcal serogroup B disease in children and adolescents (MOSAIC): a case-control study. Lancet Neurology, 11, 774-783. doi:10.1016/s1474-4422(12)70180-1.

Ware, J.E., Kosinski, M., \& Gandek, B. (1993a). SF-36 Health Survey: Manual \& Interpretation Guide. Lincoln, RI: QualityMetric Incorporated; 2000.

Ware, J.E., Snow, K.K., Kosinski, M., et al. (1993b). SF-36 Health Survey: manual and interpretation guide. Boston, Massachusetts: The Health Institute, New England Medical Center.

WHO QOL Group. (1995). World Health Organisation Quality of Life assessment (WHO QOL). Social Science and \& Medicine, 41, 1403. 